\title{
Inactivation of Hepatitis A Virus and Human Norovirus in Clams Subjected to Heat Treatment
}

\author{
Cristina Fuentes ${ }^{1,2}$, Francisco J. Pérez-Rodríguez ${ }^{1,2}$, Aurora Sabrià ${ }^{1,2}$, \\ Nerea Beguiristain ${ }^{1,2}$, Rosa M. Pintó ${ }^{1,2}$, Susana Guix ${ }^{1,2 *}$ and Albert Bosch ${ }^{1,2 *}$ \\ 1 Enteric Virus Laboratory, Department of Genetics, Microbiology and Statistics, University of Barcelona, Barcelona, Spain, \\ ${ }^{2}$ Nutrition and Food Safety Research Institute (INSA.UB), University of Barcelona, Barcelona, Spain
}

OPEN ACCESS

Edited by:

Doris DSouza,

The University of Tennessee, Knoxville, United States

Reviewed by: Dan Li,

National University of Singapore,

Singapore

Laurent Guillier

Agence Nationale de Sécurité

Sanitaire de l'Alimentation,

de l'Environnement et du Travail

(ANSES), France

Dapeng Wang,

Shanghai Jiao Tong University, China

*Correspondence:

Susana Guix

susanaguix@ub.edu

Albert Bosch

abosch@ub.edu

Specialty section:

This article was submitted to

Food Microbiology,

a section of the journal

Frontiers in Microbiology

Received: 30 June 2020 Accepted: 17 December 2020

Published: 12 January 2021

Citation:

Fuentes C, Pérez-Rodríguez FJ, Sabrià A, Beguiristain N, Pintó RM,

Guix S and Bosch A (2021)

Inactivation of Hepatitis A Virus and Human Norovirus in Clams

Subjected to Heat Treatment.

Front. Microbiol. 11:578328. doi: 10.3389/fmicb.2020.578328
Bivalve mollusk contamination by enteric viruses, especially human noroviruses (HuNoV) and hepatitis A virus (HAV), is a problem with health and economic implications. The aim of the study was the evaluation of the effect of heat treatment in clams (Tawera gayi) experimentally contaminated with HuNoV using a PMA-viability RTqPCR assay to minimize measurement of non-infectious viruses, and used HAV as a model to estimate infectivity loss. Spiked clams were immersed in water at $90^{\circ} \mathrm{C}$ to ensure that internal meat temperature was maintained above $90^{\circ} \mathrm{C}$ for at least $5 \mathrm{~min}$. The treatment resulted in $>3.89 \pm 0.24 \log _{10} \mathrm{TCID}_{50} / \mathrm{g}$ reduction of infectious HAV, confirming inactivation. For HuNoV, RTqPCR assays showed $\log _{10}$ reductions of $2.96 \pm 0.79$ and $2.56 \pm 0.56$, for Gl and GIl, respectively, and the use of PMA resulted in an additional $\log _{10}$ reduction for Gll, providing a better correlation with risk reduction. In the absence of a cell culture system which could be used to determine HuNoV infectivity reduction, a performance criteria based on PMA-RTqPCR log reduction could be used to evaluate food product safety. According to data from this study, heat treatments of clams which cause reductions $>3.5 \log _{10}$ for Gll as measured by PMA-RTqPCR assay may be regarded as an acceptable inactivation treatment, and could be set as a performance criterion to test the effectiveness of other time-temperature inactivation processes.

Keywords: hepatitis A virus, human norovirus, clams, heat inactivation, infectivity, PMA-viability RTqPCR

\section{INTRODUCTION}

The occurrence of gastroenteritis due to human norovirus (HuNoV) and hepatitis a virus (HAV) infections associated to the consumption of contaminated mollusks is a major public health concern. The analysis of the European baseline survey of $\mathrm{HuNoV}$ in oysters reported a prevalence of $34.5 \%$ in production areas (Romalde et al., 2018). Although surveillance studies report lower prevalences for HAV in bivalves produced within the EU (Romalde et al., 2018; Fusco et al., 2019), HAV outbreaks have occurred in association to consumption of both local (Guillois-Bécel et al., 2009; Boxman et al., 2016) and imported mollusks (Pinto et al., 2009). According to data from the European Union (EU) in 2018, enteric viruses generated 389 foodborne outbreaks affecting approximately 10,000 individuals, and $\mathrm{HuNoV}$ accounted for $20 \%$ of all outbreaks associated to fish and fishery products including shellfish and mollusks (Fusco et al., 2019). 
The most reliable virucidal method to ensure mollusk safety is thorough cooking. Heat-treatments ensuring that pathogenic microorganisms are eliminated must also be industrially applied by shellfish producers to fulfill current EU regulations for samples from Class B and C production areas which do not comply with bacteriological criteria. According to EU official classification scheme, mollusk production areas are classified as Class B when at $\geq 90 \%$ of samples contain less than 4,600 E. coli most probable number (MPN) per $100 \mathrm{~g}$ of flesh and intravalvular fluid and remaining $10 \%$ below 46,000; and as Class $\mathrm{C}$ when all samples have $<46,000$ E. coli MPN/100 g. The heat treatment of reference is the heating of the mollusk flesh to not less than $90^{\circ} \mathrm{C}$ and maintenance of this minimum temperature for a period of not less than $90 \mathrm{~s}$ (Codex, 2012), but based on studies performed with HAV, it is known that heat-up and cool-down time can lead to significant variations in viral $\log _{10}$ reduction depending on the process design (EFSA BIOHAZ Panel, 2015). A heat inactivation and risk assessment model elaborated by EFSA, based on HAV data, highlighted the need for a Performance Criterion (PC) for the whole process, which is the required log reduction during heat treatment (EFSA BIOHAZ Panel, 2015). While in the absence of heat treatment, the average predicted risk was about 1 infection per 100 servings, 4 logs reduction of HAV during heat inactivation would reduce the predicted risk down to one infection per 1,000,000 servings. For HuNoV, despite availability of a cell culture systems to propagate certain HuNoV (Ettayebi et al., 2016) strains, its application for viral inactivation studies on food matrixes is still difficult and data on inactivation kinetics have been mostly estimated by measuring genome copies only and by the use of viral surrogates (Bozkurt et al., 2015; Polo et al., 2018). Both approaches have generated data that suggest that $\mathrm{HuNoV}$ is less tolerable to heating than HAV (Bozkurt et al., 2015). As an example, D-values at $100^{\circ} \mathrm{C}$ for $\mathrm{HAV}$ and $\mathrm{HuNoV}$ estimated by reduction in viral genome copies in contaminated mussels are $1.58 \mathrm{~min}$ and $0.93-1.3 \mathrm{~min}$, respectively (Hewitt and Greening, 2006; Croci et al., 2012; Bozkurt et al., 2015).

Several inactivation studies related to food safety issues have also been addressed recently by using PMA-viability RTqPCR assays, but the number of reports on the applicability of such methods on complex matrixes such as bivalve mollusks are still low (Moreno et al., 2015; Quijada et al., 2016; Randazzo et al., 2018).

The objective of the present work was to evaluate the effect of heat treatment in mollusks experimentally contaminated with $\mathrm{HuNoV}$ and $\mathrm{HAV}$, inferred by PMA-viability RTqPCR assay to minimize measurement of non-infectious viruses. Clams were selected due to their high reported levels of HuNoV contamination (Guix et al., 2019), because they are often heat-treated by producers and/or distributors and sold as cooked, and due to the lack of published studies focusing on $\mathrm{HuNoV}$ inactivation in this type of mollusk. Heat treatment was designed so that it could be assured that internal temperature of clams was maintained above $90^{\circ} \mathrm{C}$ for at least $90 \mathrm{~s}$, following the EU regulatory guidelines, and seeking a performance criterion of at least $4 \log _{10}$ inactivation of infectious viruses (Millard et al., 1987; Lees,
2000). The generated data will be valuable to improve the thermal inactivation models existing for HAV and to contribute to the better understanding of $\mathrm{HuNoV}$ heat tolerability in shellfish.

\section{MATERIALS AND METHODS}

\section{Viral Stocks}

Stool specimens positive for HuNoV GI.6 and GII.4 (New_Orleans_2009) from patients with gastroenteritis were obtained from previously studied gastroenteritis outbreaks (Sabria et al., 2014). Ten percentage (wt/v) stool suspensions in phosphate buffered saline (PBS) buffer were prepared and viral genome concentrations were determined by RTqPCR quantification, following the protocol described at the ISO 15216-1:2017 (ISO15216$1: 2017,2017$ ), as previously described (Boxman et al., 2016). The cell-adapted cytopathogenic pHM175 43c strain of HAV (kindly provided by T. Cromeans, Centers for Disease Control and Prevention, Atlanta, GA) was grown in FRhK4 cells and concentrated virus stocks were obtained as previously described (Aragonès et al., 2008). Viral stocks were titrated by Tissue Culture Infectious Dose 50 (TCID $\left.{ }_{50}\right)$ assay in FRhK-4 cells, as well as by RTqPCR quantification following the protocol described at the ISO 15216-1:2017 (ISO15216-1:2017, 2017).

\section{Artificial Contamination of Clams}

Clams (Tawera gayi) from two batches which had been previously tested negative for $\mathrm{HuNoV}$ and HAV by ISO 15216-1:2017 (ISO15216-1:2017, 2017) method, were kindly provided by Mascato SA (Vigo, Spain). A pool of HuNoV GI, GII, and HAV viruses was prepared at a final concentration of $2.59 \times 10^{7}$, $4.25 \times 10^{8}$, and $2.12 \times 10^{11}$ viral genome copies per $\mathrm{ml}$, respectively (the concentration of $\mathrm{HAV}$ in $\mathrm{TCID}_{50} / \mathrm{ml}$ was of $\left.6.69 \times 10^{9}\right)$. Clams were spiked by manually injecting $10 \mu \mathrm{l}$ of the virus pool into the hepatopancreas of each animal using a 10$\mu l$ syringe with a very fine needle. Viruses were left to adsorb to the digestive tissue for $120 \mathrm{~min}$ at room temperature, and contaminated clams were vacuum packed in $15 \times 15 \mathrm{~cm}$ plastic bags. Twelve clams from different batches were included in each bag per condition.

\section{Thermal Inactivation}

Contaminated clams vacuum packed in $15 \times 15 \mathrm{~cm}$ plastic bags were processed by thermal treatment in a water bath at $90^{\circ} \mathrm{C}$. Samples were immersed in the water bath for $10 \mathrm{~min}$ to ensure that samples reached $90^{\circ} \mathrm{C}$ for at least $90 \mathrm{sec}$. On average, $4 \mathrm{~min}$ were required for samples to reach $90^{\circ} \mathrm{C}$ and temperature was above $90^{\circ} \mathrm{C}$ during $5 \mathrm{~min}$. Temperature within each vacuum packed bag was monitored using a digital thermograph (Datalogger EBI10). After treatment, packed clams were transferred to water at room temperature to reduce temperature, and were further frozen at $-70^{\circ} \mathrm{C}$ until processing. Each condition was replicated three times. 


\section{Sample Processing and Virus Quantification}

Digestive glands were dissected out from the 12 contaminated clams contained in each bag and were manually chopped with a razor blade to a paste-like consistency. Approximately $2 \mathrm{~g}$ digestive tissue (DT) samples were obtained from the 12 clams contained in each bag. The obtained DT samples were split in two parts to be used in the RTqPCR (HuNoV GI, GII, and HAV) and infectivity assays (HAV), respectively.

For RTqPCR assays, the DT mass was diluted at a 1:1.5 proportion in proteinase $\mathrm{K}$ solution $(3 \mathrm{U} / \mathrm{ml})$. Ten microliteres of a process control Mengovirus stock were added to each sample and they were digested for $1 \mathrm{~h}$ at $37^{\circ} \mathrm{C}$ and $15 \mathrm{~min}$ at $60^{\circ} \mathrm{C}$. The suspension was centrifuged at $800 \mathrm{~g}$ for $5 \mathrm{~min}$ at $4^{\circ} \mathrm{C}$, the pellet was discarded, and this was considered the DT homogenate. $500 \mu \mathrm{l}$ of the DT homogenate were processed using the NucliSens ${ }^{\otimes}$ miniMAG magnetic kit (BioMérieux) according to the manufacturer's instructions. Nucleic acids were eluted in $100 \mu \mathrm{l}$ and RTqPCR quantification was performed following the protocol described at the ISO 15216-1:2017 (ISO15216-1:2017, 2017). Limit of detection (LOD) of the RTqPCR analysis of HAV, HuNoV GI and HuNoV GII on shellfish using the ISO 152161:2017 was of 198, 34 and 53 Genome copies/g DT, respectively (Lowther et al., 2019).

For PMA-viability RTqPCR assays, $50 \mu \mathrm{l}$ of the DT homogenate were diluted $1: 10$ in a final volume of $500 \mu \mathrm{l}$ of distilled water containing $50 \mu \mathrm{M}$ of PMA (Biotinum). The mixtures were incubated in the dark for $5 \mathrm{~min}$ at $300 \mathrm{rpm}$, and were then exposed to light for 15 min using a photo activation system (Led-Active Blue, Geniul). Subsequently, nucleic acid extraction and RTqPCR quantification was performed following the protocol described at the ISO 15216-1:2017 (ISO152161:2017, 2017).

For determination of infectious viral titer, the DT mass was mixed with GBEB (Glycine Beef Extract Buffer: 1.5\% beef extract in glycine $0.05 \mathrm{M}) \mathrm{pH} 9.5$ at a proportion $1: 3$, and incubated at room temperature for $20 \mathrm{~min}$ at $30 \mathrm{rpm}$. The suspension was centrifuged at $800 \mathrm{~g}$ for $15 \mathrm{~min}$ at $4^{\circ} \mathrm{C}$ and the pellet was discarded. The supernatant was diluted 1:1 with Minimal Essential Medium (MEM) and the $\mathrm{pH}$ was adjusted at $7 \pm 0.5$. The sample was decontaminated by the addition of chloroform at $30 \%(\mathrm{v} / \mathrm{v})$ and vigorous mixing. The aqueous phase was recovered by centrifugation at 9,300 $\mathrm{g}$ for $10 \mathrm{~min}$ at room temperature. Chloroform traces were removed through aeration of the supernatant, and the final recovered volume was measured. Infectious HAV titers were determined using the TCID $_{50}$ method in FRhK-4 cells (Manso and Romalde, 2013), testing a total volume of $1.6 \mathrm{ml}$ for each sample. All samples were titrated in duplicate.

\section{Data Analysis}

Viral recoveries were calculated by dividing the virus recovered from each sample (bag containing 12 clams) by the total amount of viruses inoculated in each sample, using the formula \% Recovery $=$ Measured Recovered Virus Concentration/(Total Viruses Spiked in 12 clams/Total DT g obtained from 12 clams $) \times 100$. Effect of heat treatment on virus reduction was determined by calculating the $\log$ reduction units $\left(\mathrm{N}_{t} / \mathrm{N}_{0}\right)$, where $\mathrm{N}_{0}$ is the titer of virus recovered on untreated control samples and $\mathrm{N}_{t}$ is the titer of virus recovered on heat inactivated samples. Differences between groups were determined by one-way analysis of variance (ANOVA) and HSD Tukey's test, using the VassarStats website $^{1}$. A $p$-value $<0.05$ was deemed significant.

\section{RESULTS}

The efficiency of virus extraction procedures from experimentally spiked clams were calculated using unheated samples and are shown in Table 1. While efficiencies for both $\mathrm{HuNoV}$ genogroups were above $1 \%$, efficiencies for HAV were below $1 \%$ both by measuring infectious viruses as well as viral genomes. In all cases, recoveries of Mengovirus process control were above $1 \%(3.21 \pm 0.18 \%)$ as required in the ISO 15216 1:2017 (ISO15216-1:2017, 2017), and RTqPCR inhibition was not detected in any sample.

For viral inactivation experiments, spiked clam samples were immersed in a water bath at $90^{\circ} \mathrm{C}$ within vacuum packed bags, and temperature within each bag was monitored using a thermograph. Figure 1 shows the average temperature recorded during the process. On average, $4 \mathrm{~min}$ were required for samples to reach $90^{\circ} \mathrm{C}$ and temperature was above $90^{\circ} \mathrm{C}$ during $5 \mathrm{~min}$.

Experiments confirmed a $\log _{10}$ reduction of $>3.89 \pm 0.24 \log$ $\mathrm{TCID}_{50} / \mathrm{g}$ for infectious HAV, confirming that treatment performed caused viral inactivation, and as expected measurement of viral inactivation by RTqPCR assay alone produced a much lower $\log _{10}$ reduction (Table 2). For HuNoV, RTqPCR assays showed higher $\log _{10}$ reductions than for HAV

${ }^{1}$ http://vassarstats.net/index.html

TABLE 1 | Recovery efficiencies of spiked viruses (average \pm standard deviation).

\begin{tabular}{|c|c|c|c|}
\hline Viral target & Spiked & Recovered & $\%$ Recovery $^{a}$ \\
\hline \multicolumn{4}{|c|}{ (a) $T C / D_{50}$ assay $^{\mathrm{b}}$} \\
\hline HAV & $8.60 \pm 0.07$ & $5.75 \pm 0.32$ & $0.16 \pm 0.11$ \\
\hline \multicolumn{4}{|c|}{ (b) RTqPCR assayc,d } \\
\hline $\mathrm{HAV}$ & $10.11 \pm 0.07$ & $7.32 \pm 0.40$ & $0.24 \pm 0.27 \mathrm{AB}$ \\
\hline HuNoV Gl & $6.19 \pm 0.07$ & $4.18 \pm 0.26$ & $1.17 \pm 0.87 \mathrm{ABC}$ \\
\hline HuNoV Gll & $7.33 \pm 0.05$ & $5.62 \pm 0.19$ & $2.05 \pm 0.78 \mathrm{C}$ \\
\hline
\end{tabular}

${ }^{a}$ Recoveries for each sample (bag containing 12 clams) were calculated using the formula \% Recovery = Measured Recovered Virus Concentration/(Total Viruses Spiked in 12 clams/Total DT g obtained from 12 clams) $\times 100$. Titers were expressed as TCID 50 or Genome copies/g DT. As an example for HAV measured by $T C I D_{50}$ assay, 12 clams from one sample were inoculated with a total of $7.93 \times 10^{8}$ $T C I D_{50}$, and a total of $1.77 \mathrm{~g}$ were obtained after dissecting all 12 clams. Since HAV concentration measured after animal DT analysis was $5.50 \times 10^{5} \mathrm{TCI} \mathrm{D}_{50} / \mathrm{g}$ DT, \% recovery was $5.50 \times 10^{5} /\left(7.93 \times 10^{8} / 1.77\right) \times 100=0.12 \%$. Table shows mean values \pm standard deviations from three samples.

${ }^{b}$ Spiked and recovered levels are expressed as $L$ og $T C I D_{50} / g$ DT.

c Spiked and recovered levels are expressed as Log Genome copies/g DT.

'Values with different capital letters in the third column denote significant differences between viruses ( $p<0.05$ ). 


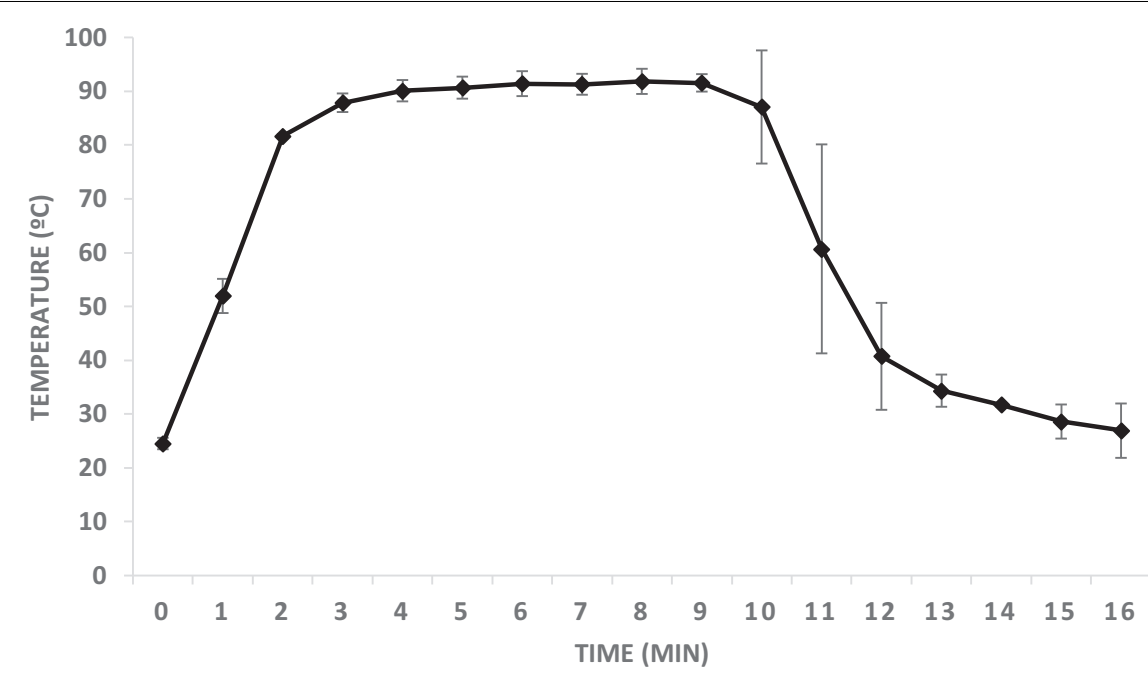

FIGURE 1 | Temperature monitoring during the inactivation process. Data correspond to average \pm standard deviation calculated from three independent experiments.

(2.96 \pm 0.79 and $2.56 \pm 0.56$, for GI and GII, respectively), according to a lower tolerance to heat, but differences were not statistically significant $(\mathrm{p}=0.088)$. Finally, the use of PMA provided a better correlation with infectivity, with additional $\log _{10}$ reductions of 1.41 and 0.96 , for HAV and GII, respectively. Viral titers for HAV and GII untreated samples measured by RTqPCR and PMA-RTqPCR assays and expressed as Genome copies/g DT were similar. PMA on GI contaminated samples could not be applied due to insufficient viral titers. The lack of signal in the untreated controls after PMA treatment could be due to the fact that a $1 / 10$ dilution of the DT was made before addition of PMA in order to ensure its optimal action, and also be to the occurrence of damaged GI capsids in the stool specimen used for spiking. Since temperature profile was dynamic (Figure 1) and no intermediate data

TABLE 2 | Titers and log reductions (average \pm standard deviation) for hepatitis A virus (HAV), HuNoV Gl, and Gll in clams during heat inactivation.

\begin{tabular}{|c|c|c|c|}
\hline & $\begin{array}{c}\text { Untreated } \\
\text { samples }\left(\mathrm{N}_{0}\right)\end{array}$ & $\begin{array}{l}\text { Heat-treated } \\
\text { samples }\left(\mathrm{N}_{t}\right)\end{array}$ & $\log N_{t} / N_{0}$ \\
\hline \multicolumn{4}{|l|}{ (a) HAV } \\
\hline $\mathrm{TCID}_{50}$ assay $^{\mathrm{a}}$ & $5.75 \pm 0.32$ & $<1.85 \pm 0.02$ & $>3.89 \pm 0.24$ \\
\hline RTqPCR assay ${ }^{b}$ & $7.32 \pm 0.40$ & $5.57 \pm 0.35$ & $-1.75 \pm 0.13$ \\
\hline PMA-RTqPCR assay ${ }^{b}$ & $7.79 \pm 0.36$ & $4.63 \pm 1.21$ & $-3.16 \pm 1.46$ \\
\hline \multicolumn{4}{|l|}{ (b) HuNoV Gl } \\
\hline RTqPCR assay ${ }^{b}$ & $4.18 \pm 0.26$ & $1.22 \pm 0.59$ & $-2.96 \pm 0.79$ \\
\hline PMA-RTqPCR assay ${ }^{b}$ & $<$ LOD & $<$ LOD & NA \\
\hline \multicolumn{4}{|l|}{ (c) HuNoV GIl } \\
\hline RTqPCR assay ${ }^{b}$ & $5.62 \pm 0.19$ & $2.97 \pm 0.40$ & $-2.56 \pm 0.56$ \\
\hline PMA-RTqPCR assay ${ }^{b}$ & $5.86 \pm 0.35$ & $2.34^{\mathrm{C}}$ & $-3.52^{\mathrm{C}}$ \\
\hline
\end{tabular}

were collected during heat treatment, D values could not be assessed precisely.

\section{DISCUSSION}

In the present study, heat inactivation of HAV and HuNoV on clams (Tawera gayi) was evaluated, by using a heat treatment which assured that internal temperature of clams was maintained above $90^{\circ} \mathrm{C}$ for at least $90 \mathrm{~s}$, following the EU regulatory guidelines. HAV was used as the most heat-resistant model virus which allow infectivity measurement. Experiments were designed in order to achieve a performance criterion of $>4 \log _{10}$ reduction of infectious viruses, but the difficulty in obtaining HAV stocks with extremely high titers allowed us to confirm a $\log _{10}$ reduction of $>3.89$ because the titer fell below the limit of detection of our assay. According to the process lethality determination model made available by the Foundation for Meat and Poultry Research and Education ${ }^{2}$, and the HAV D and $\mathrm{z}$ reference values published by EFSA BIOHAZ Panel (2015), the log reduction estimated by the heat treatment performed in our study would be 10.65 , ensuring a complete virucidal effect. When assessed by PMA-RTqPCR, a molecular assay which has been shown to allow infectivity estimates for other food matrices (Moreno et al., $2015)$, this performance corresponded to a $\log _{10}$ reduction of $3.16 \pm 1.46$.

Although inactivation of $\mathrm{HuNoV}$ is normally only assessed by molecular methods and/or surrogates, published data indicate that it is less tolerable to heating than HAV (Hewitt and Greening, 2006; Croci et al., 2012; Bozkurt et al., 2015). The Human Intestinal Enteroid (HIE) infection model also demonstrated complete inactivation of GII.3 and GII.4 by heating at $60^{\circ} \mathrm{C}$ for as little as $15 \mathrm{~min}$ (Ettayebi et al., 2016). In our study,

\footnotetext{
${ }^{2}$ https://meatpoultryfoundation.org/content/process-lethality-spreadsheet
} 
both RTqPCR and PMA-RTqPCR measurements confirmed that heat-resistance of $\mathrm{HuNoV}$ is lower than HAV.

The use of PMA-RTqPCR viability assays has been previously tested and optimized for $\mathrm{HAV}$ and $\mathrm{HuNoV}$, to be applied on complex mollusk samples (Moreno et al., 2015; Randazzo et al., 2018). For HAV, the use of 10 -fold diluted cockle or clam DT homogenate and pretreatment with $50 \mu \mathrm{M}$ PMA combined with $0.5 \%$ Triton X-100 allowed the minimization of the detection of spiked thermally inactivated viruses (Moreno et al., 2015). For $\mathrm{HuNoV}$, pretreatment was optimized by using $100 \mu \mathrm{M}$ PMAxx with $0.5 \%$ Triton $\mathrm{X}-100$ and increasing incubation and photoactivation processes, and oysters contaminated by bioaccumulations were used (Randazzo et al., 2018). None of these studies completely eliminated the quantification of genomes despite the performance of heat-treatments which would provide complete inactivation. Our protocol was based on the use of 10-fold diluted clam DT homogenate coupled with $50 \mu \mathrm{M}$ PMA. It allowed additional $\log _{10}$ reductions of 1.41 and 0.96 , for HAV and GII, respectively, as compared with RTqPCR alone, without completely preventing amplification of inactivated genomes. These $\log _{10}$ reductions are similar to what has been described previously in cockles and clams inoculated with high doses of $5 \mathrm{~min} / 99^{\circ} \mathrm{C}$ heat-inactivated HAV (1.45 and 1.53) (Moreno et al., 2015) and oysters bioaccumulated with GI and GII HuNoV and heat-processed for $15 \mathrm{~min}$ at $95^{\circ} \mathrm{C}$ (0.85 and 1.07) (Randazzo et al., 2018), confirming a similar method performance.

According to our result, PMA-viability RTqPCR method could be used to estimate whether a certain inactivation process reaches the desired performance criterion for $\mathrm{HuNoV}$ inactivation. Thus, heat treatments of $\mathrm{HuNoV}$ contaminated clams which cause reductions $>3.5 \log _{10}$ as measured by PMA-viability RTqPCR (or $>2.5 \log _{10}$ as measured by RTqPCR following the ISO method) may be equivalent to acquiring $>3.89 \log _{10} \mathrm{HAV}$ inactivation. A performance criterion for a certain heat-inactivation process for $\mathrm{HuNoV}$ set at $>3.5 \log _{10}$ reduction, as measured by PMA-viability RTqPCR could be pursued to significantly minimize $\mathrm{HuNoV}$ risk. This could also be useful to test different timetemperature combinations, both during industrial and culinary processes, which could be applied to live clams from class and $\mathrm{C}$ production areas that have not been submitted for

\section{REFERENCES}

Aragonès, L., Bosch, A., and Pintó, R. M. (2008). Hepatitis a virus mutant spectra under the selective pressure of monoclonal antibodies: codon usage constraints limit capsid variability. J. Virol. 82, 1688-1700. doi: 10.1128/jvi.01842-07

Boxman, I. L. A., Verhoef, L., Vennema, H., Ngui, S.-L., Friesema, I. H. M., Whiteside, C., et al. (2016). International linkage of two food-borne hepatitis A clusters through traceback of mussels, the Netherlands, 2012. Eurosurveillance 21:30113.

Bozkurt, H., D'souza, D. H., and Davidson, P. M. (2015). Thermal inactivation of foodborne enteric viruses and their viral surrogates in foods. J. Food Prot. 78, 1597-1617. doi: 10.4315/0362-028x.jfp-14-487

Codex, A. (2012). "Guidelines on the application of general principles of food hygiene to the control of viruses in food," in Proceedings of the Codex Committee on Food Hygiene, Kampala. purification or relaying. Whether this inference could be applied to other types of shellfish and/or inactivation methods remains to be studied.

In summary, this study shows the successful use of viability PMA-RTqPCR method on complex food matrices and its potential application to evaluate whether heat-inactivation processes comply with a specific set performance criterion in terms or risk reduction. In addition, results from this study are also of value to perfect a $\mathrm{HuNoV}$ heat-inactivation model in shellfish samples.

\section{DATA AVAILABILITY STATEMENT}

The raw data supporting the conclusions of this article will be made available by the authors, without undue reservation, to any qualified researcher.

\section{AUTHOR CONTRIBUTIONS}

CF, FP-R, AS, and NB performed the experiments. RP and AB acquired funding, defined the experimental approach, revised the results, and contributed to the preparation of the first draft of the manuscript. SG defined the experimental approach, revised the results, and led the preparation of the manuscript. All authors contributed to the article and approved the submitted version.

\section{FUNDING}

This work was partially funded by project "SafeConsume: Safer food through changed consumer behavior: Effective tools and products, information strategies, education and a food safety policy reducing health burden from foodborne illnesses (No. 727580)" of European Union's 8P32FS - Horizon 2020 programme.

\section{ACKNOWLEDGMENTS}

We are thankful to Mascato Sa (Vigo, Spain) for providing clam samples.

Croci, L., Suffredini, E., Di Pasquale, S., and Cozzi, L. (2012). Detection of norovirus and feline calicivirus in spiked molluscs subjected to heat treatments. Food Control 25, 17-22. doi: 10.1016/j.foodcont.2011.10.004

EFSA BIOHAZ Panel (2015). Evaluation of heat treatments, different from those currently established in the EU legislation, that could be applied to live bivalve molluscs from $\mathrm{B}$ and $\mathrm{C}$ production areas, that have not been submitted to purification or relaying, in order to eliminate pathogenic microorganisms. EFSA J. 13:4332.

Ettayebi, K., Crawford, S. E., Murakami, K., Broughman, J. R., Karandikar, U., Tenge, V. R., et al. (2016). Replication of human noroviruses in stem cellderived human enteroids. Science 353, 1387-1393. doi: 10.1126/science.aaf5211

Fusco, G., Anastasio, A., Kingsley, D. H., Amoroso, M. G., Pepe, T., Fratamico, P. M., et al. (2019). Detection of hepatitis a virus and other enteric viruses in shellfish collected in the gulf of naples, Italy. Int. J. Environ. Res. Public Health 16:2588. doi: 10.3390/ijerph16142588 
Guillois-Bécel, Y., Couturier, E., Le Saux, J. C., Roque-Afonso, A. M., Le Guyader, F. S., Le Goas, A., et al. (2009). An oyster-associated hepatitis A outbreak in France in 2007. Eurosurveillance 14:19144.

Guix, S., Pinto, R. M., and Bosch, A. (2019). Final consumer options to control and prevent foodborne norovirus infections. Viruses 11:333. doi: 10.3390/ v11040333

Hewitt, J., and Greening, G. E. (2006). Effect of heat treatment on hepatitis A virus and norovirus in New Zealand greenshell mussels (Perna canaliculus) by quantitative real-time reverse transcription PCR and cell culture. J. Food Prot. 69, 2217-2223. doi: 10.4315/0362-028x-69.9.2217

ISO15216-1:2017 (2017). Microbiology of the Food Chain -- Horizontal Method for Determination of Hepatitis A Virus and Norovirus Using Real-time RTPCR -- Part 1: Method for Quantification. Geneva: ISO.

Lees, D. (2000). Viruses and bivalve shellfish. Int. J. Food Microbiol. 59, 81-116. doi: 10.1016/s0168-1605(00)00248-8

Lowther, J. A., Bosch, A., Butot, S., Ollivier, J., Made, D., Rutjes, S. A., et al. (2019). Validation of EN ISO method 15216 - Part 1 - Quantification of hepatitis A virus and norovirus in food matrices. Int. J. Food Microbiol. 288, 82-90. doi: 10.1016/j.ijfoodmicro.2017.11.014

Manso, C. F., and Romalde, J. L. (2013). Detection and characterization of hepatitis A virus and norovirus in mussels from Galicia (NW Spain). Food Environ. Virol. 5, 110-118. doi: 10.1007/s12560-013-9108-2

Millard, J., Appleton, H., and Parry, J. V. (1987). Studies on heat inactivation of hepatits A virus with special reference to shellfish. Epidemiol. Infect. 98, 397-414. doi: 10.1017/s0950268800062166

Moreno, L., Aznar, R., and Sanchez, G. (2015). Application of viability PCR to discriminate the infectivity of hepatitis A virus in food samples. Int. J. Food Microbiol. 201, 1-6. doi: 10.1016/j.ijfoodmicro.2015. 02.012

Pinto, R. M., Costafreda, M. I., and Bosch, A. (2009). Risk assessment in shellfishborne outbreaks of hepatitis A. Appl. Environ. Microbiol. 75, 7350-7355. doi: 10.1128/aem.01177-09
Polo, D., Schaeffer, J., Teunis, P., Buchet, V., and Le Guyader, F. S. (2018). Infectivity and RNA persistence of a norovirus surrogate, the tulane virus, in oysters. Front. Microbiol. 9:716. doi: 10.3389/fmicb.2018.00716

Quijada, N. M., Fongaro, G., Barardi, C. R., Hernandez, M., and RodriguezLazaro, D. (2016). Propidium monoazide integrated with qPCR enables the detection and enumeration of infectious enteric RNA and DNA viruses in clam and fermented sausages. Front. Microbiol. 7:2008. doi: 10.3389/fmicb.2016. 02008

Randazzo, W., Khezri, M., Ollivier, J., Le Guyader, F. S., Rodriguez-Diaz, J., Aznar, R., et al. (2018). Optimization of PMAxx pretreatment to distinguish between human norovirus with intact and altered capsids in shellfish and sewage samples. Int. J. Food Microbiol. 266, 1-7. doi: 10.1016/j.ijfoodmicro.2017. 11.011

Romalde, J. L., Rivadulla, E., Varela, M. F., and Barja, J. L. (2018). An overview of 20 years of studies on the prevalence of human enteric viruses in shellfish from Galicia, Spain. J. Appl. Microbiol. 124, 943-957. doi: 10.1111/jam.13614

Sabria, A., Pinto, R. M., Bosch, A., Bartolome, R., Cornejo, T., Torner, N., et al. (2014). Molecular and clinical epidemiology of norovirus outbreaks in Spain during the emergence of GII.4 2012 variant. J. Clin. Virol. 60, 96-104. doi: 10.1016/j.jcv.2014.03.013

Conflict of Interest: The authors declare that the research was conducted in the absence of any commercial or financial relationships that could be construed as a potential conflict of interest.

Copyright (c) 2021 Fuentes, Pérez-Rodríguez, Sabrià, Beguiristain, Pintó, Guix and Bosch. This is an open-access article distributed under the terms of the Creative Commons Attribution License (CC BY). The use, distribution or reproduction in other forums is permitted, provided the original author(s) and the copyright owner(s) are credited and that the original publication in this journal is cited, in accordance with accepted academic practice. No use, distribution or reproduction is permitted which does not comply with these terms. 